\title{
Equilibrium of the intracellular redox state for improving cell growth and L-lysine yield of Corynebacterium glutamicum by optimal cofactor swapping
}

\author{
Jian-Zhong Xu ${ }^{1 *} \mathbb{B}$, Hao-Zhe Ruan ${ }^{1}$, Xiu-Lai Chen², Feng Zhang ${ }^{1}$ and Weiguo Zhang ${ }^{1}$
}

\begin{abstract}
Background: $\mathrm{NAD}\left(\mathrm{H}^{+}\right)$and $\mathrm{NADP}\left(\mathrm{H}^{+}\right)$are the most important redox cofactors in bacteria. However, the intracellular redox balance is in advantage of the cell growth and production of $\mathrm{NAD}(\mathrm{P}) \mathrm{H}$-dependent products.

Results: In this paper, we rationally engineered glyceraldehyde-3-phosphate dehydrogenase (GAPDH) and isocitrate dehydrogenase (IDH) to switch the nucleotide-cofactor specificity resulting in an increase in final titer [from 85.6 to $121.4 \mathrm{~g} \mathrm{~L}^{-1}$ ] and carbon yield [from 0.33 to $0.46 \mathrm{~g}$ (g glucose) $)^{-1}$ ] of $\mathrm{L}$-lysine in strain RGl in fed-batch fermentation. To do this, we firstly analyzed the production performance of original strain $\mathrm{JL}-6$, indicating that the imbalance of intracellular redox was the limiting factor for L-lysine production. Subsequently, we modified the native GAPDH and indicated that recombinant strain RG with nonnative NADP-GAPDH dramatically changed the intracellular levels of $\mathrm{NADH}$ and NADPH. However, L-lysine production did not significantly increase because cell growth was harmed at low NADH level. Lastly, the nonnative NAD-IDH was introduced in strain RG to increase the NADH availability and to equilibrate the intracellular redox. The resulted strain RGI showed the stable ratio of NADPH/NADH at about 1.00, which in turn improved cell growth $\left(\mu_{\max .}=0.31 \mathrm{~h}^{-1}\right)$ and L-lysine productivity $\left(q_{\text {Lys, } \max .}=0.53 \mathrm{~g} \mathrm{~g}^{-1} \mathrm{~h}^{-1}\right)$ as compared with strain $R G\left(\mu_{\max }=0.14 \mathrm{~h}^{-1}\right.$ and $\left.q_{\text {Lys, } \text { max. }}=0.42 \mathrm{~g} \mathrm{~g}^{-1} \mathrm{~h}^{-1}\right)$.
\end{abstract}

Conclusions: This is the first report of balancing the intracellular redox state by switching the nucleotide-cofactor specificity of GAPDH and IDH, thereby improving cell growth and L-lysine production.

Keywords: Corynebacterium glutamicum, Glyceraldehyde-3-phosphate dehydrogenase, Isocitrate dehydrogenase, Redox state, Cofactor optimization, L-Lysine production

\section{Background}

Corynebacterium glutamicum has three major redox systems, i.e., $\mathrm{NAD}\left(\mathrm{H} /{ }^{+}\right), \mathrm{NADP}\left(\mathrm{H} /{ }^{+}\right)$and reduced/oxidized glutathione (GSH/GSSG), which are used to adjust the intracellular redox state [1]. They are also involved in other physiological functions, including regulating the energy transfer, controlling the cell life cycle, monitoring the cellular signaling and modulating the microbial

\footnotetext{
*Correspondence: xujianzhong@jiangnan.edu.cn

${ }^{1}$ The Key Laboratory of Industrial Biotechnology, Ministry of Education, School of Biotechnology, Jiangnan University, 1800\# Lihu Road, Wuxi 214122, China

Full list of author information is available at the end of the article
}

virulence $[1-3] . \mathrm{NAD}\left(\mathrm{H} /{ }^{+}\right)$and $\mathrm{NADP}\left(\mathrm{H} /{ }^{+}\right)$, as the most important redox cofactors in metabolism, not only provide reducing power for the energy-conserving redox reactions but also act as electron acceptors in the catabolic substrates [4]. However, $\operatorname{NAD}\left(\mathrm{H} /{ }^{+}\right)$is preferentially used in catalyzing substrate oxidation, whereas $\operatorname{NADP}\left(\mathrm{H} /{ }^{+}\right)$is mainly used in catalyzing substrate reduction $[5,6]$. Therefore, balancing the oxidation-reduction state of $\mathrm{NAD}\left(\mathrm{H} /{ }^{+}\right)$and $\mathrm{NADP}\left(\mathrm{H} /{ }^{+}\right)$is crucial for both catabolism and anabolism. Some examples have illustrated the importance of redox balance and availability for producing the fine chemicals including amino acids [7-9], vitamins [10,11] and lipids [12, 13]. L-Lysine, as an 
essential amino acid for animals and humans, is mainly produced by C. glutamicum or its derivatives, which were created by traditional mutagenesis-screening techniques or by genetic engineering $[14,15]$. Notably, $4 \mathrm{~mol}$ of NADPH must be supplied for $1 \mathrm{~mol}$ of L-lysine biosynthesis from oxaloacetate, and thus numerous studies have focused on engineering the metabolism of NADPH for improving L-lysine producing strains [9, 16-19]. For example, genetic modification of the native glyceraldehyde-3-phosphate dehydrogenase (GAPDH) has been proven to improve the L-lysine production because of the increase of NADPH availability $[17,19,20]$.

GAPDH catalyzes an essential step in the glycolysis pathway (Fig. 1), which is classified into two types according to their coenzyme specificity, namely, NADand NADP-dependent GAPDHs (NAD-GAPDH and NADP-GAPDH) [21]. C. glutamicum has two
GAPDHs, i.e., GapA (NAD-dependent enzyme) and GapB (NADP ${ }^{+}$-dependent enzyme), but overexpression of GapB-coding gene is bad for the cell growth and L-lysine production [19]. It has been proven that replacement of the native GapA with the phosphorylated NADPGAPDH from Clostridium acetobutylicum [22] or with the non-phosphorylating NADP-GAPDH from Streptococcus mutans [19] significantly increased the production of L-lysine. In addition, site-directed modification of the GAPDH binding sites to switch the cofactor specificity can also realize the regeneration of NADPH rather than $\mathrm{NADH}$ in the GAPDH-catalyzed step and thus increasing the L-lysine production [20]. It should be noted that the redox pairs are tightly coupled forming a complex redox network in the cell [1]. The excess of NADPH or the insufficient of NADH inhibits the cell growth and carbon consumption. However, many studies are focused mainly

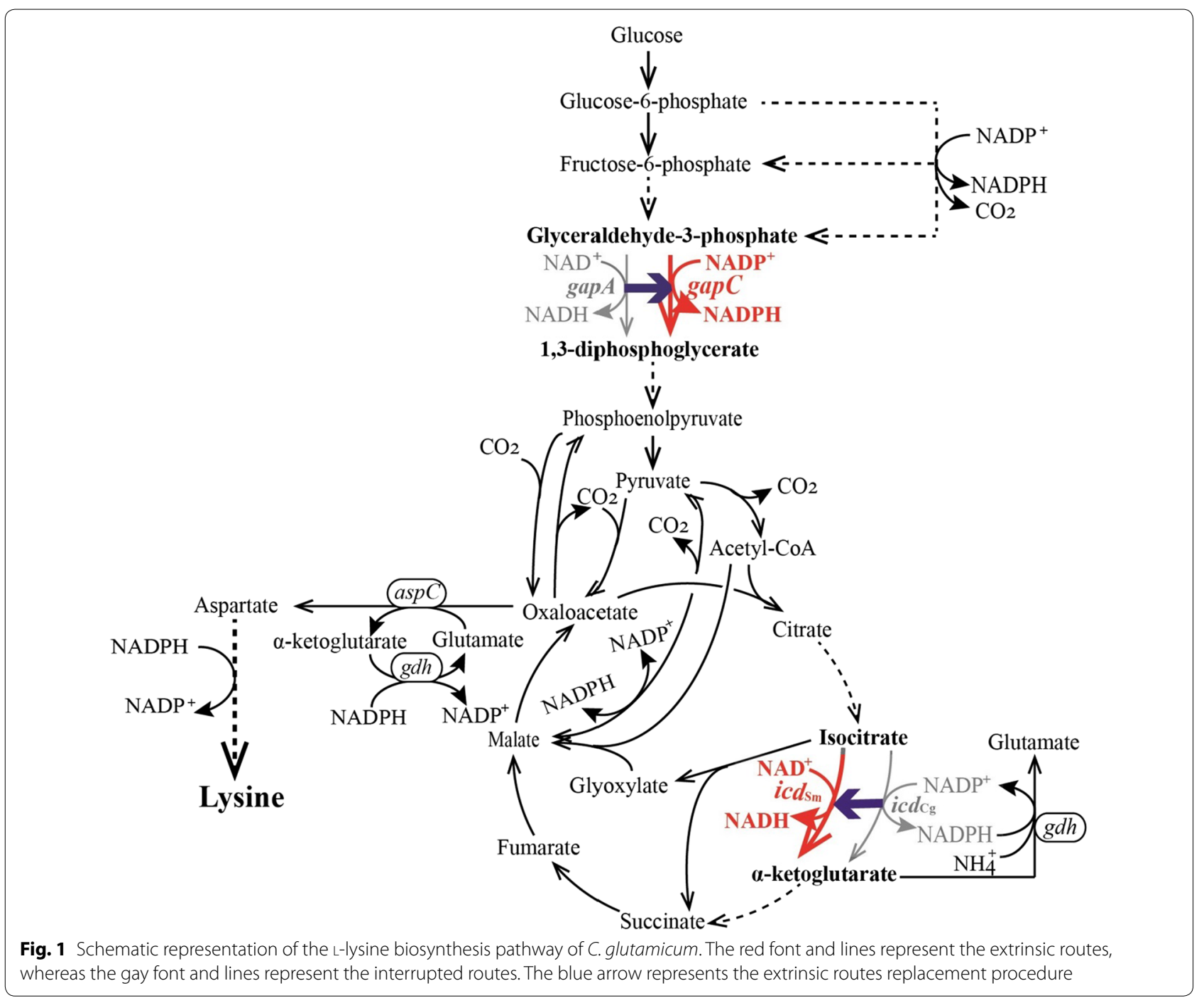


on maximizing the level of intracellular NADPH with no regard for NADH (reviewed in Ref. [6]). Therefore, how to balance the intracellular NAD ${ }^{+}$and NADPH is a critical issue during producing NADPH-dependent products.

In C. glutamicum, the reaction catalyzed by the native isocitrate dehydrogenase $(\mathrm{CgIDH})$ in the tricarboxylic acid (TCA) cycle is considered as one of NADPHgenerating reaction, because this enzyme displays a 50,000-fold preference for $\mathrm{NADP}^{+}$over $\mathrm{NAD}^{+}$[23]. In contrast, the IDH from Streptococcus mutans (SmIDH) shows the strict $\mathrm{NAD}^{+}$dependency [24]. Zhu et al. [25] reported that replacing the Escherichia coli IDH (NADP$E c \mathrm{IDH})$ with the engineered $E_{c} \mathrm{IDH}^{\text {Lys344Asp-Tyr345Ile- }}$ Val351Ala $\left(\mathrm{NAD}-\mathrm{IDH}^{\mathrm{K} 344 \mathrm{D}-\mathrm{Y} 345 \mathrm{I}-\mathrm{V} 351 \mathrm{~A}}\right.$ ) improved the cell growth of the strains with deletion of $u d h A$ because of the increase of NADH. It should be noted that very few researches focused on $\mathrm{CgIDH}$ engineering for breeding the NADPH-dependent products high-yielding strains (e.g., L-lysine high-yielding strains) based on cofactor engineering, to our knowledge. However, the focus of the present study is the replacement of the native NADPIDH by NAD-IDH from $S$. mutans to switch specificity from $\mathrm{NADP}^{+}$to $\mathrm{NAD}^{+}$in C. glutamicum. We provide experimental evidence that replacement of native NADGAPDH with NADP-GAPDH as well as replacement of native NADP-IDH with NAD-IDH will balance the intracellular NADH and NADPH, thus improves cell growth and L-lysine production. This is the first report of balancing the intracellular redox state by switching the nucleotide-cofactor specificity of GAPDH combined with IDH, thereby improving cell growth and L-lysine production.

\section{Results and discussion}

\section{The performance of $C$. glutamicum JL-6 is investigated} in fed-batch fermentation in fermenter

To get the performance parameters of C. glutamicum JL-6, the fermentation was carried out in a 5 - $\mathrm{L}$ jar fermenter containing $1 \mathrm{~L}$ fermentation media. As can be seen from Fig. 2a, the consumed sugar was major used to cell growth and thus resulted in a little L-lysine production during the initial batch phase. The major increase of L-lysine production was achieved during the feeding phase, and continuously increased to a final titer of $85.6 \pm 3.7 \mathrm{~g} \mathrm{~L}^{-1}$ (Fig. 2a). Except for L-lysine, the cell excreted about $6.0 \pm 0.8 \mathrm{~g} \mathrm{~L}^{-1}$ L-valine, $2.2 \pm 0.4 \mathrm{~g} \mathrm{~L}^{-1}$ L-leucine, $3.4 \pm 0.6 \mathrm{~g} \mathrm{~L}^{-1}$ L-isoleucine, $6.7 \pm 0.3 \mathrm{~g} \mathrm{~L}^{-1}$ L-threonine and $10.1 \pm 0.5 \mathrm{~g} \mathrm{~L}^{-1} \mathrm{~L}$-glutamine into the broth (Fig. 2b). Same with the L-lysine production, the
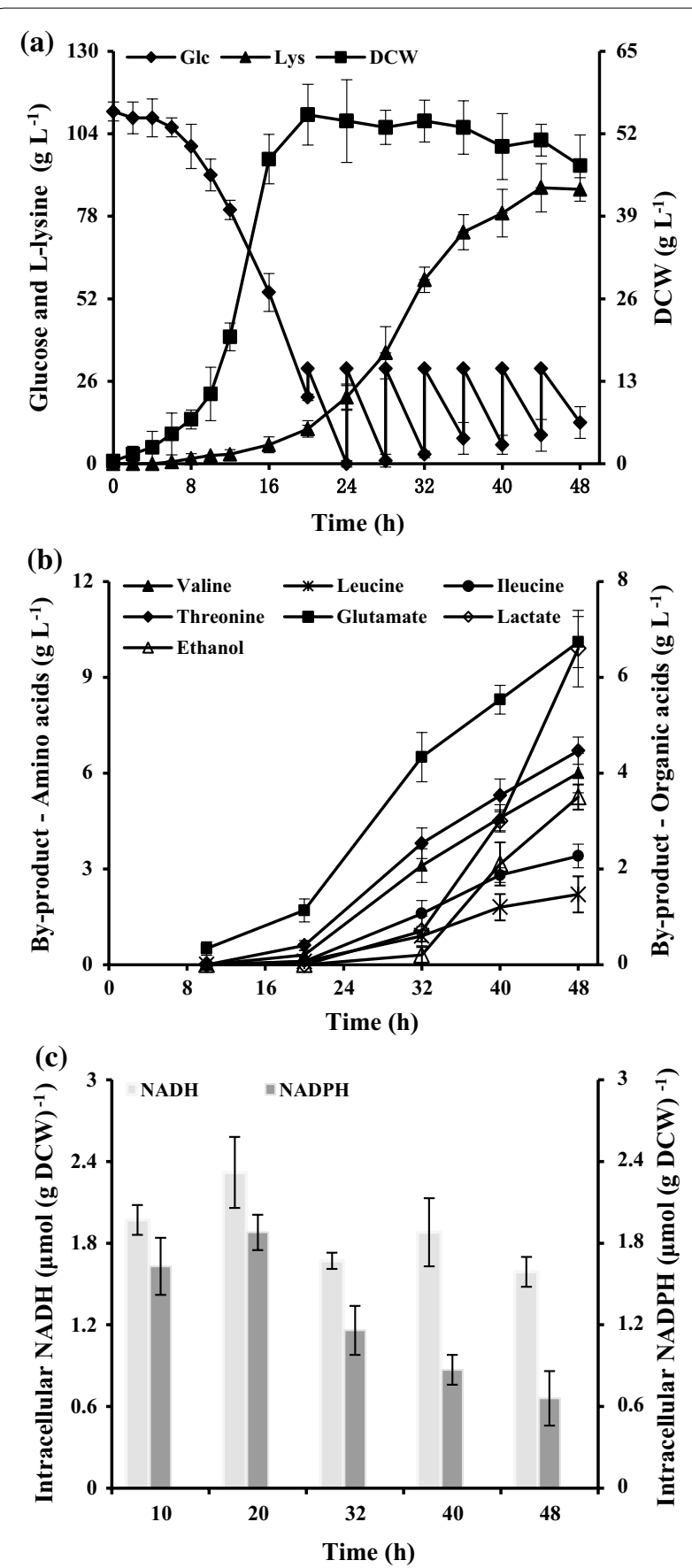

Fig. 2 The L-lysine production (filled triangle), cell growth (filled square) and glucose (filled diamond) (a), by-products accumulation (b), and intracellular level of nucleotide-cofactor (c) in strain JL-6 during cultivating in 5 - $\mathrm{L}$ fermentors. The total glucose consumption of strain $\mathrm{J} L-6$ was $260 \mathrm{~g} \mathrm{~L}^{-1}$. The data represent mean values and standard deviations obtained from three independent cultivations 
production of BCAAs (i.e., L-valine, L-leucine, and L-isoleucine) and L-threonine also requires the cofactor NADPH [6]. It should be noted that the rate of glucose uptake and L-lysine production were decreased at the end of fermentation (Fig. 2a). Our previous results [14] and Martinez et al. [26] reports indicated that the GAPDH in glycolysis is inhibited by NADH, and could be a reason of the decrease in the glucose update and L-lysine production. However, NADH-dependent by-products (e.g., lactate and ethanol) concentrations were strongly increased at the end of fermentation (Fig. 2b). This is because intracellular NADH accumulation stimulates the production of NADH-dependent products [27]. In order to confirm the effect of the intracellular NADH/NADPH level on the performance of strain, the changes of intracellular level of NADH or NADPH were monitored over the course of the experiment (Fig. 2c). As might be expected, the intracellular NADH level was at an all-time high, and the NADPH level drastically decreased at the end of fermentation. In addition, the ratio of $\mathrm{NADH} / \mathrm{NAD}^{+}$was also at a high level at the logarithmic growth phase (Additional file 1: Table S1). Taken together, these results indicated that C. glutamicum JL-6 should be modified based on cofactor engineering to increase L-lysine yield.

\section{Replacing NAD-GAPDH with NADP-GAPDH increases NADPH production but hampers cell growth}

NAD-GAPDH in C. glutamicum was a mainly enzyme for synthesizing NADH [19]. In order to reduce the ratio of NADH/NAD ${ }^{+}$and to increase the NADPH availability, we replaced the native NAD-GAPDH with NADPGAPDH from $C$. acetobutylicum, and the performance of recombinant strain JL-6 $\triangle$ gapA::gapC (i.e., C. glutamicum RG) were monitored over the cause of the experiment. The genetically modified strain RG showed no detectable specific NAD-GAPDH activity but exhibited $232.1 \pm 15.7 \mathrm{mU}\left(\mathrm{mg}^{-1}\right.$ protein) of NADP-GAPDH, whereas the original strain JL-6 showed $279.5 \pm 12.5 \mathrm{mU}$ $\left(\mathrm{mg}^{-1}\right.$ protein) of NAD-GAPDH and no detectable specific NADP-GAPDH activity (Table 1). Accordingly, the $\mathrm{NADH}$ level and the ratio of $\mathrm{NADH} / \mathrm{NAD}^{+}$was significantly decreased, but the NADPH level and the ratio of $\mathrm{NADPH} / \mathrm{NADP}^{+}$was increased in strain RG as compared with strain JL-6 (Fig. 3c and Additional file 1: Table S1). Interestingly, the L-lysine production had not obviously increased along with the NADPH level enhancement (Fig. 3a). This is because strain RG showed a bad cell growth as compared with original strain JL-6, i.e., $35.2 \pm 4.5 \mathrm{~g} \mathrm{~L}^{-1}$ and $47.1 \pm 3.8 \mathrm{~g} \mathrm{~L}^{-1}$, respectively (Table 2). The similar results were also found in the previous report, and it proved that the NADPH level is too high to imbalance the reducing power [19]. In addition, Zhu et al. [25] pointed out that the cell growth retarded
Table 1 In vitro specific activities of enzymes in genetically modified $C$. glutamicum strains and original strain C. glutamicum JL-6 as well as wild-type C. glutamicum ATCC13032

\begin{tabular}{|c|c|c|c|c|}
\hline \multirow{3}{*}{$\begin{array}{l}\text { C. } \\
\text { glutamicum } \\
\text { strains }\end{array}$} & \multicolumn{4}{|c|}{ Specific activity [mU (mg protein $\left.)^{-1}\right]$} \\
\hline & \multicolumn{2}{|l|}{ GAPDH } & \multicolumn{2}{|l|}{ IDH } \\
\hline & $\mathrm{NAD}^{+}$ & $\mathrm{NADP}^{+}$ & $\mathrm{NAD}^{+}$ & $\mathrm{NADP}^{+}$ \\
\hline$J L-6$ & $279.5 \pm 12.5$ & - & $4.5 \pm 1.4$ & $232.5 \pm 19.8$ \\
\hline$R G$ & - & $232.1 \pm 15.7$ & $8.9 \pm 1.1$ & $216.2 \pm 27.3$ \\
\hline RGI & - & $253.1 \pm 21.2$ & $194.5 \pm 21.6$ & - \\
\hline
\end{tabular}

The assay mixture contained $1 \mathrm{mmol} \mathrm{L}^{-1} \mathrm{NAD}^{+}$or NADP ${ }^{+}$as cofactor, and one unit of enzyme activity corresponds to $1 \mu \mathrm{mol}$ NADH or NADPH formed per min, which was monitored continuously at $A_{340}$

All data are meaning values of three determinations of three independent experiments with $\pm S D$

- , not detected

for lack of energy caused by insufficient NADH availability. However, it is heartening that the production strength of strain RG was higher than that of the original strain JL-6, i.e., $2.63 \mathrm{~g}(\mathrm{~g} \mathrm{DCW})^{-1}$ and $1.82 \mathrm{~g}(\mathrm{~g} \mathrm{DCW})^{-1}$, respectively. Moreover, NADH-dependent by-products (e.g., lactate and ethanol) concentrations were strongly decreased at the end of fermentation (Fig. 3b). These results indicated that the production performance of strain RG must be further optimized by balancing the intracellular redox state to increase the cell growth.

\section{Replacing NADP-IDH with NAD-IDH balances the intracellular redox state}

The native CgIDH in C. glutamicum is one of NADPHgenerating enzyme, whereas the IDH from $S$. mutans $(S m I D H)$ showed strict $\mathrm{NAD}^{+}$dependency [24]. In order to increase the NADH availability and to balance the intracellular redox state, we replaced the native NADPdependent IDH (NADP-IDH) with NADP-dependent IDH (NAD-IDH) from S. mutans, and the performance of recombinant strain RG $\Delta i c d_{\mathrm{Cg}}: i c d_{\mathrm{Sm}}$ (i.e., C. glutamicum RGI) were monitored over the cause of the experiment. The genetically modified strain RGI showed no detectable specific NADP-IDH activity but exhibited $194.5 \pm 21.6 \mathrm{mU}\left(\mathrm{mg}^{-1}\right.$ protein) of NAD-IDH, whereas the strain RG showed $216.2 \pm 27.3 \mathrm{mU}\left(\mathrm{mg}^{-1}\right.$ protein) of NADP-IDH and $8.9 \pm 1.1 \mathrm{mU}\left(\mathrm{mg}^{-1}\right.$ protein) of NAD-IDH (Table 1). Cvitkovitch et al. [24] pointed out that $S m I D H$ is a strict $\mathrm{NAD}^{+}$-dependent enzyme, thus no NADP-IDH activity was detected in strain RGI. As was expected, the cell growth was well improved and the glucose consumption rate of strain RGI was higher than that of strain RG (Figs. 3a, 4a; Table 2). The similar results were also found in the previous reports, in which 

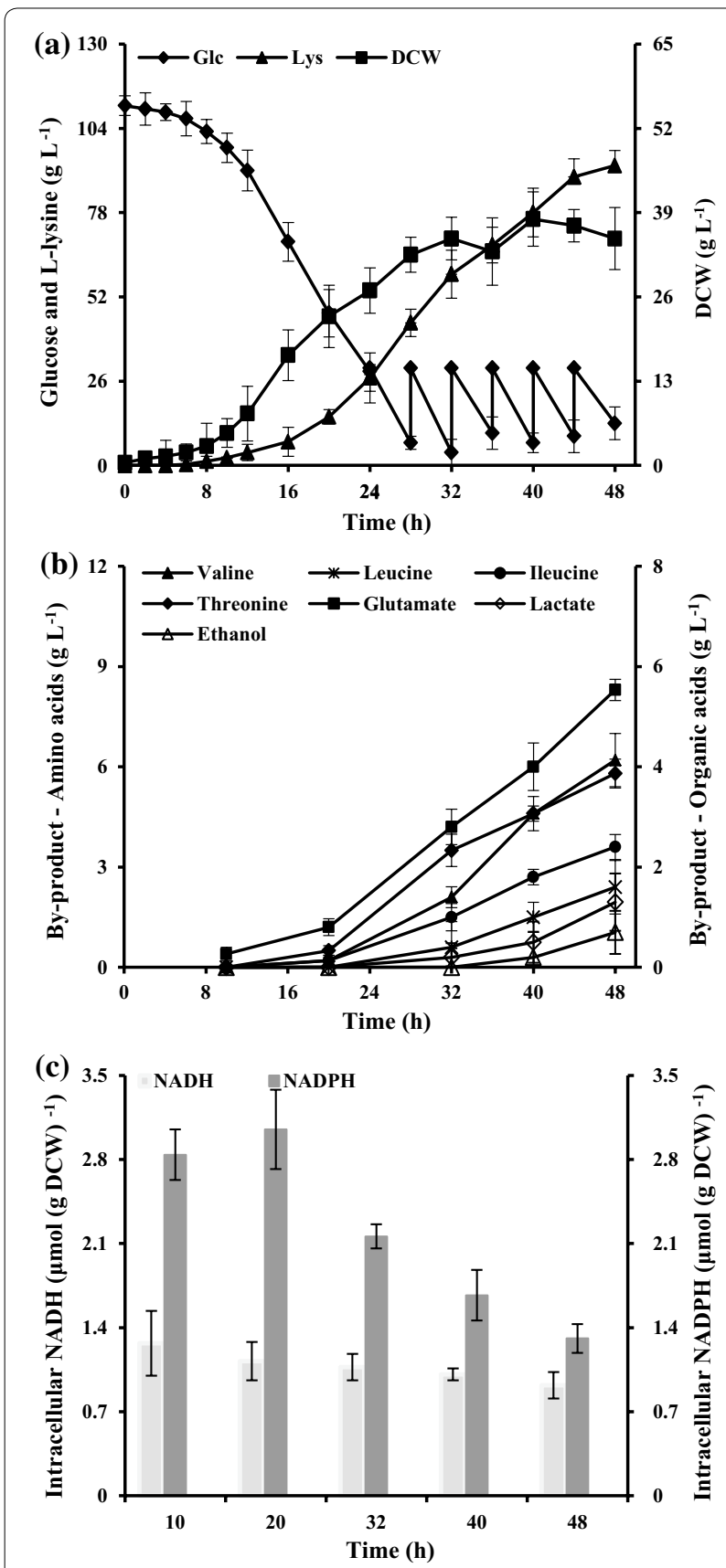

Fig. 3 The L-lysine production (filled triangle), cell growth (filled square) and glucose (filled diamond) (a), by-products accumulation (b), and intracellular level of nucleotide-cofactor (c) in strain RG during cultivating in 5-L fermentors. The total glucose consumption of strain RG was $212 \mathrm{~g} \mathrm{~L}^{-1}$. The data represent mean values and standard deviations obtained from three independent cultivations
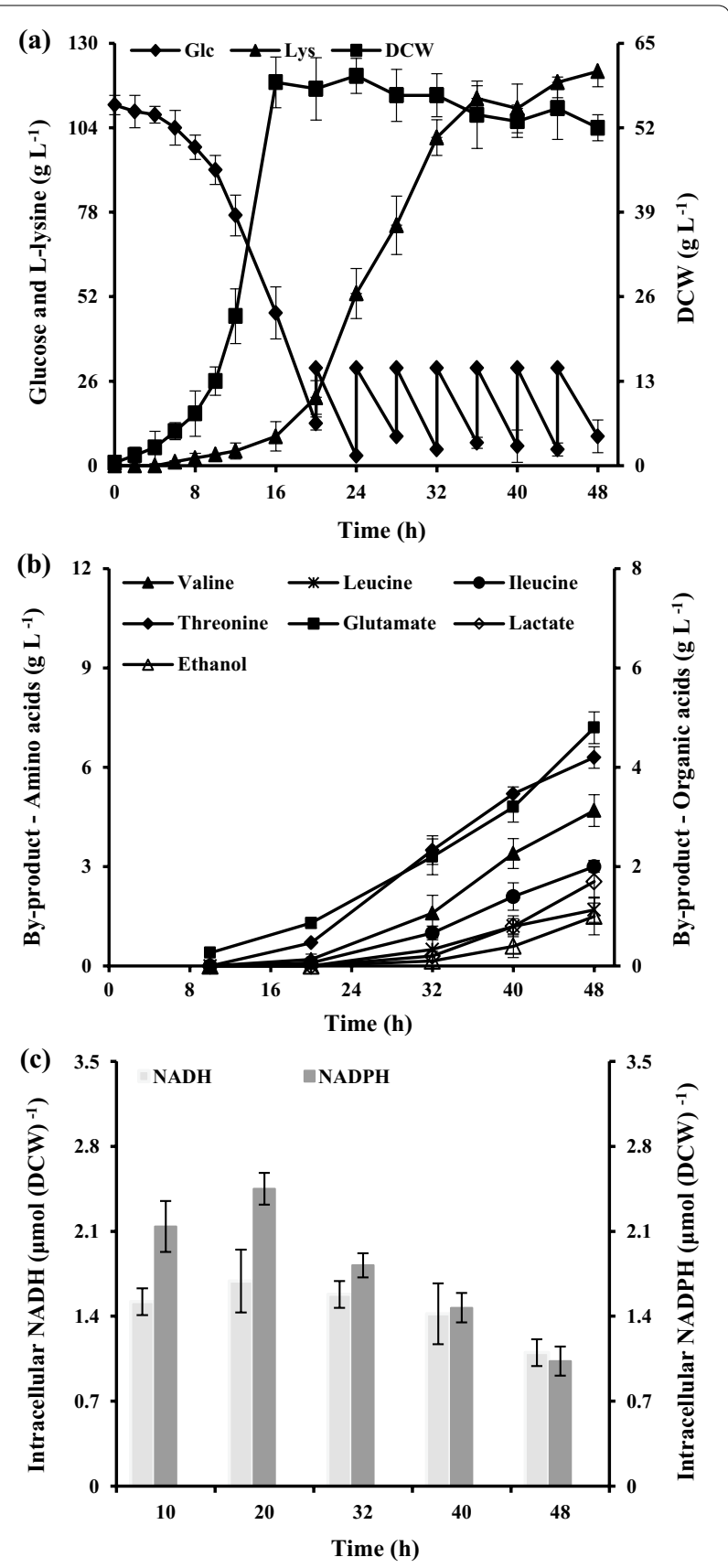

Fig. 4 The L-lysine production (filled triangle), cell growth (filled square) and glucose (filled diamond) (a), by-products accumulation (b), and intracellular level of nucleotide-cofactor (c) in strain RGI during cultivating in 5 -L fermentors. The total glucose consumption of strain RGI was $264 \mathrm{~g} \mathrm{~L}^{-1}$. The data represent mean values and standard deviations obtained from three independent cultivations the non-proton-pumping NADH:ubiquinone oxidoreductase (NDH-II) was mutated to switch its nucleotidecofactor specificity by introducing the D213G mutation in the wild-type enzyme [22] or a spontaneous mutants with improved growth on glucose was isolated [19]. The L-lysine production of strain RGI, of cause, increased significantly with the replacement of IDH. The strain RGI excreted $121.4 \pm 4.8 \mathrm{~g} \mathrm{~L}^{-1}$ L-lysine with a space-time 
Table 2 The DCW ( $24 \mathrm{~h}$ or $48 \mathrm{~h}$ ), L-lysine production ( $24 \mathrm{~h}$ or $48 \mathrm{~h}$ ), maximal specific growth rate $\left(\mu_{\text {max. }}\right)$, maximal specific production rate of L-lysine $\left(q_{\mathrm{Lys}}\right.$, max. $)$, maximal specific substrate uptake rate of glucose $\left(q_{\mathrm{s}, \text { max. }}\right)$ and glucose conversion efficiency (a) of C. glutamicum strains

\begin{tabular}{|c|c|c|c|c|c|c|c|c|}
\hline \multirow{2}{*}{$\begin{array}{l}\text { C. glutamicum } \\
\text { strains }\end{array}$} & \multicolumn{2}{|c|}{$\mathrm{DCW}\left(\mathrm{g} \mathrm{L}^{-1}\right)$} & \multicolumn{2}{|c|}{ L-Lys yield $\left(\mathrm{g} \mathrm{L}^{-1}\right)$} & \multirow[t]{2}{*}{$\mu_{\max }{ }^{a}\left(h^{-1}\right)$} & \multirow[t]{2}{*}{$q_{\text {Lys, max. }}{ }^{b}\left(g^{-1} h^{-1}\right)$} & \multirow[t]{2}{*}{$q_{s, \max .}{ }^{c}\left(g g^{-1} h^{-1}\right)$} & \multirow[t]{2}{*}{$a^{d}(\%)$} \\
\hline & $24 \mathrm{~h}$ & $48 \mathrm{~h}$ & $24 \mathrm{~h}$ & $48 \mathrm{~h}$ & & & & \\
\hline$J L-6$ & $54.3 \pm 6.5$ & $47.1 \pm 3.8$ & $21.4 \pm 4.1$ & $85.6 \pm 3.7$ & 0.23 & $0.26 \pm 0.05$ & $0.80 \pm 0.15$ & 32.9 \\
\hline RG & $26.3 \pm 3.6$ & $35.2 \pm 4.5$ & $27.2 \pm 6.3$ & $92.5 \pm 2.6$ & 0.14 & $0.42 \pm 0.08$ & $0.65 \pm 0.32$ & 43.6 \\
\hline RGI & $60.3 \pm 5.8$ & $52.5 \pm 2.8$ & $53.1 \pm 7.9$ & $121.4 \pm 4.8$ & 0.31 & $0.53 \pm 0.06$ & $0.93 \pm 0.24$ & 50.0 \\
\hline
\end{tabular}

All data are meaning values of three determinations of three independent experiments with $\pm S D$

a The maximal specific growth rate of cell in the whole fermentation cycle

b The maximal specific production rate of L-lysine in the whole fermentation cycle

c The maximal specific substrate uptake rate of glucose in the whole fermentation cycle

$\mathrm{d}$ The conversion rate of glucose into L-lysine after cultivating $48 \mathrm{~h}$

yield of $2.53 \mathrm{~g} \mathrm{~L}^{-1} \mathrm{~h}^{-1}$ and a maximal specific production rate $\left(q_{\text {Lys, max. }}\right)$ of $0.53 \pm 0.06 \mathrm{~g} \mathrm{~g}^{-1} \mathrm{~h}^{-1}$, whereas the strain RG only accumulated $92.5 \pm 2.6 \mathrm{~g} \mathrm{~L}^{-1} \mathrm{~L}$-lysine with a space-time yield of $1.93 \mathrm{~g} \mathrm{~L}^{-1} \mathrm{~h}^{-1}$ and a maximal specific production rate $\left(q_{\mathrm{Lys}, \text { max. }}\right)$ of $0.42 \pm 0.08 \mathrm{~g} \mathrm{~g}^{-1} \mathrm{~h}^{-1}$ (Table 2). These results are in contrast with the reports of Becker et al. [28]; they found that decrease the ICD (also known as IDH) activity is beneficial for improving L-lysine production because of increasing the flux of anaplerotic carboxylation. And for this we modified the $S m I D H$ activity by replacing the promoter of SmIDHcoding gene $i c d_{\mathrm{Sm}}$ in strain RGI. Five classes of promoters (i.e., $\mathrm{P}_{\text {dapA-L1 }}, \mathrm{P}_{\text {tac }}, \mathrm{P}_{\text {tac-M }}, \mathrm{P}_{\text {tuf }}$ and $\mathrm{P}_{\text {sod }}$ ) were used in this study. Among them, the $\mathrm{P}_{\text {dapA-L1 }}$ is a weak promoter, whereas the $\mathrm{P}_{\text {tac- } \mathrm{M}}, \mathrm{P}_{\text {tuf }}$ and $\mathrm{P}_{\text {sod }}$ are the strong promoters in C. glutamicum as compared with the $\mathrm{P}_{\text {tac }}$ [29]. Interestingly, the strains with the higher or the lower NAD-IDH activity were bad for cell growth and L-lysine production as compared with strain RGI (Table 3). We speculated that there would be two reasons: it may be controlled by L-glutamate production or by energy charge. The energy charge is too low to meet the requirement of cell growth, thus bad for L-lysine production during the strains with the lower NAD-IDH activity (Table 3 ). In contrast, the bad cell growth and the low L-lysine production of strains with the higher NAD-IDH activity may be due to the insufficient supply of L-glutamate. Müller [30] indicated that IDH- and glutamate dehydrogenase-catalytic reactions shape a conjugate pattern in redox reaction. NADIDH catalyzes the NADH synthesis rather than NADPH [24], whereas the reaction catalyzed by glutamate dehydrogenase needs NADPH as cofactor [30]. Therefore, the strains with the higher NAD-IDH activity accumulate the little L-glutamate because of the insufficient supply of NADPH. The speculation of these reasons has been validated on examining the concentration of by-products as well as pyridine nucleotides $\mathrm{NAD}\left(\mathrm{H} /{ }^{+}\right)$and $\operatorname{NADP}\left(\mathrm{H} /{ }^{+}\right)$
(Fig. 4b, c). The accumulation of L-glutamate decreased to $7.2 \pm 0.17 \mathrm{~g} \mathrm{~L}^{-1}$ in strain RGI from $8.3 \pm 0.36 \mathrm{~g} \mathrm{~L}^{-1}$ in strain RG (Fig. 4b). Interestingly, the other NADPHdependent by-products (e.g., L-valine, L-leucine and $\mathrm{L}$ - isoleucine) were also decreased to a certain extent, whereas the production of L-threonine was slightly increased (Fig. 4b). This could be that more pyruvate was used to biosynthesize aspartate-family amino acids (e.g., L-threonine and L-lysine) rather than to biosynthesize pyruvate-family amino acids (e.g., L-valine, L-leucine and L-isoleucine). In addition, the strain RGI has certain improvement in the NADH level and the ratio of NADH/ NAD (Fig. 4c and Additional file 1: Table S1). More importantly, the NADPH level was just on proper level and the ratio of NADPH/NADH remained fairly constant in the late fermentation stage at about 1.00 in strain RGI (Fig. 4c).

\section{Changes of carbon flux in strains JL-6, RG and RGI}

As mentioned above, replacing the GAPDH or/and IDH increased the performance of L-lysine fermentation as compared with the original strain JL-6. To study the effects of GAPDH and IDH on L-lysine production, the changes of carbon flux in JL-6, RG and RGI were studied using GC-MS. More than 70 intracellular metabolites showed different levels in JL-6, RG and RGI. Among these 80 metabolites, 22 of them were closely related to L-lysine production in the biosynthetic pathway. To get more detailed view of the changes of carbon flux caused by the replacement of GAPDH and IDH, the relative content of these 22 metabolites were determined in the postlogarithmic phase (Additional file 1: Table S2). Compared with strain JL-6, the contents of intermediates in glycolysis were significantly increased in strain RGI, and conversely these intermediates were slightly decreased in strain RG (Fig. 5). The reasons may be that the imbalance of intracellular redox state disturbed the glucose 


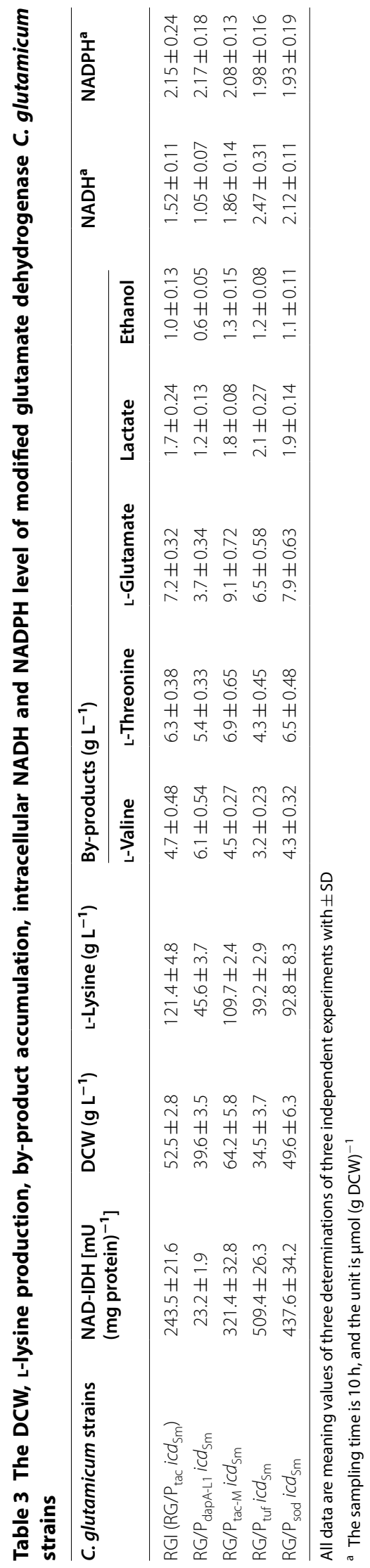




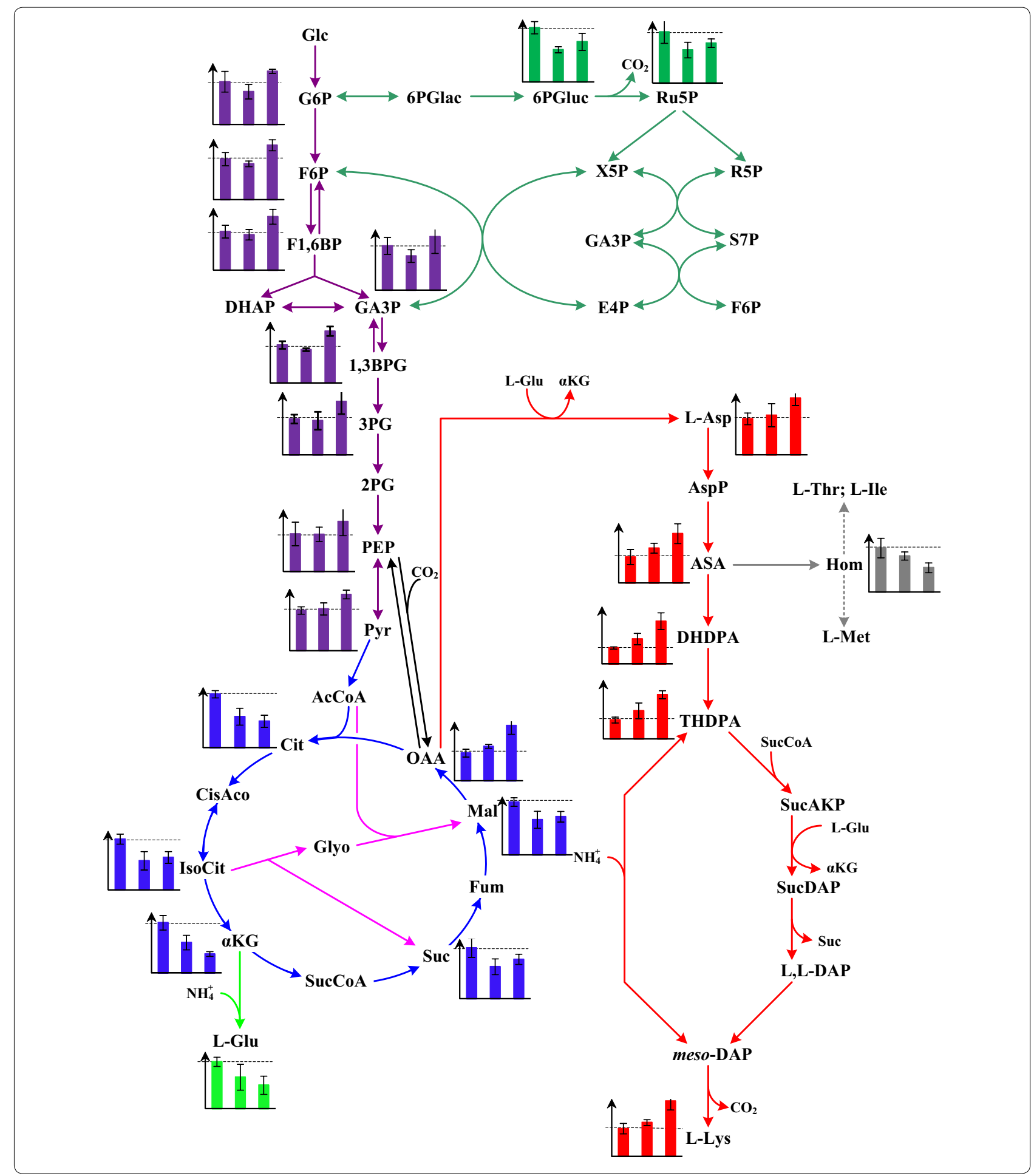

uptake of strains because of the replacing the GAPDH $[19,25]$, whereas further replacing the IDH in strain RG leads to balance the intracellular redox state (Additional file 1: Table S1). Interestingly, the carbon flux in pentose phosphate (PP) pathway was lower in strains RG and
RGI than in strain JL-6 (Fig. 5). Takeno et al. pointed out that replacement of NAD-GAPDH with NADP-GAPDH shared the function of PP pathway for supplying NADPH [19]. Previous results also indicated that replacement of NAD-GAPDH with NADP-GAPDH reduced the 
(See figure on previous page.)

Fig. 5 Levels of intermediates involved in L-lysine biosynthesis detected in strains JL-6, RG and RGI. The x-axes represent JL-6, RG and RGI. The y-axes represent the relative abundance of intermediate, which was calculated by normalizing the peak area of metabolite against the total peak area within the sample. G/c glucose, G6P glucose-6-phosphate, F6P fructose-6-phosphate, F1,6BP Fructose-1,6-bisphosphate, DHAP Dihydroxyacetone phosphate, GA3P glyceraldehydes-3-phosphate, 1,3BPG 1,3-diphosphoglycerate, 3PG 3-phosphoglycerate, 2PG 2-phosphoglycerate, PEP phosphoenol pyruvate, Pyr pyruvate, AcCoA acety-CoA, Cit citrate, CisAco cis-aconitate, IsoCit, isocitrate; a-KG, a-ketoglutarate, SucCoA, succinyl-CoA, Suc succinate, Fum fumarate; Mal malate, OAA Oxaloacetate, L-Glu L-glutamate, 6PGlac 6-phosphoglucono-1,5-lactone, 6PGluc 6-phosphogluconate, Ru5P ribulose-5-phosphate, X5P xylulose-5-phosphate, $R 5 P$ ribose-5-phosphate, S7P sedoheptulose-7-phosphate, E4P erythrose-4-phosphate, L-Asp L-aspartate, AspP L-aspartate phosphate, ASA L-aspartate-4-semialdehyde, DHDPA L-2,3-dihydrodipicolinate, THDPA L- $\triangle^{1}$-tetrahydrodip icolinate, SUCAKP L-N-succinyl-2-amino-6-ketopimelate, SUCDAP N-succinyl-L,L-2,6-diaminopimelate, L,L-DAP L,L-diaminopimelate, meso-DAP meso-diaminopimelate, L-Lys L-lysine

release of $\mathrm{CO}_{2}$ from PP pathway, thereby increasing the yield of the target products $[17,31]$. However, the contents of intermediates in TCA cycle were dramatically decreased during introduction of NADP-GAPDH or/ and NAD-IDH except oxaloacetate, which is the precursor for L-lysine biosynthesis (Fig. 5). Oxaloacetate will turn to the following metabolites in L-lysine biosynthetic pathway with the help of NADPH, thus avoiding the high NADPH in intracellular because $4 \mathrm{~mol}$ of NADPH must be supplied for $1 \mathrm{~mol}$ of L-lysine biosynthesis [6]. It should be noted that the level of $\alpha$-ketoglutarate was much lower, whereas the levels of isocitrate, succinate and malate were slightly higher in RGI than in RG. Isocitrate can be catalyzed by isocitrate lyase into glyoxylate bypass that produces succinate and malate [32]. Being short of IDH (Table 1), more isocitrate enter into glyoxylate bypass and that may be the reason for increasing the levels of isocitrate, succinate and malate. Predictably, the contents of intermediates in terminal pathway of L-lysine biosynthesis were dramatically increased in recombination strains. It should be noted that L-homoserine, as byproduct of L-lysine production, was much lower in RGI than in JL-6 and RG (Fig. 5).

\section{Conclusions}

In this work, optimal cofactor swapping by introducing different pyridine nucleotide-dependent enzymes has proved to be an ideal choice for maintaining the balance of the intracellular redox state, which is in advantage of the cell growth and production of the NAD $(\mathrm{P}) \mathrm{H}$-dependent products, including L-lysine. What's clear from this study is that replacing the native NAD-GAPDH with NADP-GAPDH and the native NADP-IDH with NADIDH balances the intracellular NADH and NADPH levels, thus improves cell growth and L-lysine production.

The replacement of native NAD-GAPDH with NADPGAPDH in the L-lysine-producing strain JL-6 has been shown to have a positive role on L-lysine production since the $4 \mathrm{~mol}$ of NADPH must be supplied for $1 \mathrm{~mol}$ of L-lysine biosynthesis. However, it is not beneficial for cell growth because of the shortage of NADH. To alleviate this, we replaced the native NADP-IDH with NAD-IDH from $S$. mutans for the first time to switch the nucleotide-cofactor specificity of IDH, and found that it was beneficial for balancing the intracellular level of $\mathrm{NADH}$ and NADPH which in turn improved cell growth and L-lysine production. Fed-batch fermentation of strain RGI resulted in $121.4 \pm 4.8 \mathrm{~g} \mathrm{~L}^{-1}$ of L-lysine with a space-time yield of $2.53 \mathrm{~g} \mathrm{~L}^{-1} \mathrm{~h}^{-1}$ and a maximal specific production rate $\left(q_{\text {Lys, max }}\right)$ of $0.53 \pm 0.06 \mathrm{~g} \mathrm{~g}^{-1} \mathrm{~h}^{-1}$. In addition, the other NADPH-dependent by-products (e.g., L-valine, L-leucine and L-isoleucine) were also decreased to a certain extent. However, the production of $\mathrm{L}$-threonine in the strain RGI was higher than that in the strain RG. Therefore, further improvement of L-lysine production with the strain RGI will act to decrease or block-up the accumulation of other NADPH-dependent by-products though the attenuation or knock-out of key gene. Although the efficiency of L-lysine production of strain RGI is relatively low, the L-lysine yield is higher than those reported in literature (Additional file 1: Table S3). Thus, the final strain RGI deserves studying further to increase the production efficiency. To do this, the carbon flux in metabolic network should be optimized in the next work, for example, switching more carbon flux into L-lysine pathway and reducing the carbon loss.

\section{Methods}

\section{Strains, growth medium and culture conditions}

Strains used in this study are listed in Table 4. L-Lysine producing strain C. glutamicum JL-6 (C. glutamicum $\mathrm{AEC}^{\mathrm{r}} \mathrm{SD}^{\mathrm{r}} \mathrm{FP}^{\mathrm{s}} \mathrm{Met}^{\mathrm{l}}$ ) derived from C. glutamicum ATCC 13032 after multiple rounds of random mutagenesis, which was resistant to $S$-2-aminoethyl-L-cysteine (AEC ${ }^{\text {r }}$ and sulfadiazine $\left(\mathrm{SD}^{\mathrm{r}}\right)$, and was sensitive to $\beta$-fluoropyruvate $\left(\mathrm{FP}^{\mathrm{s}}\right)$ as well as a leaky mutant for $\mathrm{L}$-methionine (Met $\left.{ }^{l}\right)$. This strain has been deposited in the China Information Center of Industrial Microbial, and the number is CICIM B1031.

Luria-Bertani (LB) and LBG (LB+5 $\mathrm{g} \mathrm{L}^{-1}$ glucose) were used for culturing E. coli and C. glutamicum, 
respectively [33]. Epo medium, used for preparing electroporation-competent $C$. glutamicum cells, and LBHIS (LB, Brain Heart Infusion, and sorbitol) medium, used for obtaining recombinant strains, were prepared according to the description reported by van der Rest et al. [34]. Appropriately, E. coli was incubated with $50 \mu \mathrm{g} \mathrm{mL}$ of kanamycin $(\mathrm{Km})$, and $25 \mu \mathrm{g} \mathrm{mL} \mathrm{m}^{-1}$ of $\mathrm{Km}$ was used to obtain recombinant $C$. glutamicum strains.

The fed-batch fermentations were carried out in a $5-\mathrm{L}$ jar fermenter (BLBio-5GJ-2-H, Bailun Bi-Technology Co. Ltd., Shanghai, China) containing $1 \mathrm{~L}$ of medium with an inoculum size of $10 \%(\mathrm{v} / \mathrm{v})$, from a seed culture grown to $\Delta \mathrm{OD}_{562}=0.45-0.50$ (at a dilution of 25-fold). The seed medium consisted of (per liter): 25 g glucose, $30 \mathrm{~g}$ corn steep liquor, $5 \mathrm{~g}\left(\mathrm{NH}_{4}\right)_{2} \mathrm{SO}_{4}, 1 \mathrm{~g} \mathrm{KH}_{2} \mathrm{SO}_{4}, 0.5 \mathrm{~g}$ $\mathrm{MgSO}_{4} \cdot 7 \mathrm{H}_{2} \mathrm{O}, 0.25 \mathrm{~g}$ L-methionine and $10 \mathrm{~g} \mathrm{CaCO}_{3}$. The fermentation medium contained (per liter): $80 \mathrm{~g}$ glucose, $40 \mathrm{~g}$ beet molasses, $30 \mathrm{~g}$ corn steep liquor, $50 \mathrm{~g}$ $\left(\mathrm{NH}_{4}\right)_{2} \mathrm{SO}_{4}, 1.5 \mathrm{~g} \mathrm{KH}_{2} \mathrm{SO}_{4}, 1.0 \mathrm{~g} \mathrm{MgSO}_{4} \cdot 7 \mathrm{H}_{2} \mathrm{O}, 0.02 \mathrm{~g}$ $\mathrm{FeSO}_{4}, 0.02 \mathrm{~g} \mathrm{MnSO}_{4}, 0.5 \mathrm{~g}$ L-methionine, $0.05 \mathrm{~g}$ glycine betaine, $400 \mu \mathrm{g}$ thiamine- $\mathrm{HCl}, 800 \mu \mathrm{g}$ biotin and $2 \mathrm{~mL}$ antifoam. The aeration rate, $\mathrm{pH}$, dissolved oxygen levels, and temperature were set as described by Becker et al. [35]. Feed solution, containing $800 \mathrm{~g} \mathrm{~L}^{-1}$ sterile glucose and $400 \mathrm{~g} \mathrm{~L}^{-1}\left(\mathrm{NH}_{4}\right)_{2} \mathrm{SO}_{4}$, was used to maintain a glucose concentration at $20-30 \mathrm{~g} \mathrm{~L}^{-1}$ by adjusting the feeding rate according to the glucose concentration checked every $4 \mathrm{~h}$.

\section{DNA manipulations and construction of $C$. glutamicum recombinant strains}

The plasmids and oligonucleotides used in this study are listed in Table 4 and Additional file 1: Table S4, respectively. C. glutamicum DNA was extracted, and was used as template for the target gene clone using corresponding primers (Additional file 1: Table S4). The cassette of SmIDH-coding gene with $P_{\text {tac }}$ promoter, $r r n B T 1 T 2$ terminator and SalI endonuclease was synthetized by General Biosystems (Anhui), Inc. (Chuzhou, China). The plasmid construction and transformation were performed according to the descriptions of previous reports [17].

The replacements of gene and promoter were executed in C. glutamicum chromosome according to the published method [17, 29]. The recombinant plasmids were transferred into C. glutamicum competent cell by electroporation, and the recombinant strains were screened on the LBHIS agar plates containing $25 \mu \mathrm{g} \mathrm{mL}{ }^{-1}$ of $\mathrm{Km}$

Table 4 Strains and plasmids used in this study

\begin{tabular}{|c|c|c|}
\hline Strains and plasmids & Relevant characteristic(s) & References \\
\hline \multicolumn{3}{|l|}{ Strains } \\
\hline E. coli BL21 (DE3) & $\mathrm{F}^{-}$ompT galdcm lon hsdS ${ }_{B}\left(r_{B} m_{B}\right) \lambda(D E 3)$ & Stratagene \\
\hline C. glutamicum JL-6 (i.e., CICIM B1031) & $\begin{array}{l}\text { C. glutamicum AEC' SD' FPs Met', derived from strain ATCC13032, deposited in China Information } \\
\text { Center of Industrial Microbial (CICIM) }\end{array}$ & CICIM \\
\hline C. glutamicum RG & $\begin{array}{l}\text { Replacement of the natural gapA gene with the } \mathrm{P}_{\text {tac }}-g a p C-r r n B T 1 T 2 \text { cassette in strain JL-6 chromo- } \\
\text { some }\end{array}$ & This work \\
\hline $\begin{array}{l}\text { C. glutamicum RGI (i.e., C. glutami- } \\
\left.\text { cum } R G / P_{\text {tac }} i{ }^{\prime} d_{S m}\right)\end{array}$ & $\begin{array}{l}\text { Replacement of the natural icd } \\
\text { some }\end{array}$ & This work \\
\hline C. glutamicum RG/P dapA-L1 $i c d_{S m}$ & $\begin{array}{l}\text { Replacement of the natural } i c d_{C g} \text { gene with the } P_{\text {dapA-L1 }}-i c d_{S m}-r r n B T 1 T 2 \text { cassette in strain RG } \\
\text { chromosome }\end{array}$ & This work \\
\hline C. glutamicum $\mathrm{RG} / \mathrm{P}_{\text {tac-M }} i c d_{\mathrm{Sm}}$ & $\begin{array}{l}\text { Replacement of the natural icd }{ }_{C g} \text { gene with the } P_{\text {tac- }}{ }^{-i c d_{S m}}-r r n B T 1 T 2 \text { cassette in strain RG chro- } \\
\text { mosome }\end{array}$ & This work \\
\hline C. glutamicum $\mathrm{RG} / \mathrm{P}_{\text {tuf }} i c d_{\mathrm{Sm}}$ & $\begin{array}{l}\text { Replacement of the natural } i c d_{C g} \text { gene with the } P_{\text {tuf }}-i c d_{S m}-r r n B T 1 T 2 \text { cassette in strain RG chromo- } \\
\text { some }\end{array}$ & This work \\
\hline C. glutamicum RG/P $\mathrm{P}_{\text {sod }}$ icd $d_{\mathrm{Sm}}$ & $\begin{array}{l}\text { Replacement of the natural } i c d_{C g} \text { gene with the } P_{\text {sod }}-i c d_{S m}-r r n B T 1 T 2 \text { cassette in strain RG chromo- } \\
\text { some }\end{array}$ & This work \\
\hline \multicolumn{3}{|l|}{ Plasmids } \\
\hline $\mathrm{pUC57/icd_{Sm }}$ & $\begin{array}{l}\text { The plasmid with the cassette of icd }{ }_{S m} \text { gene (including Ptac promoter, rrnBT1T2 terminator and } \\
i c d_{S m} \text { operon) }\end{array}$ & Synthetic \\
\hline pK18mobsacB & Integration vector & {$[40]$} \\
\hline 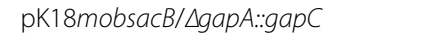 & Integration vector for replacement of the gapA gene by the $\mathrm{P}_{\text {tac }}-g a p C-r r n B T 1 T 2$ cassette & {$[17]$} \\
\hline pK18mobsacB/ $\Delta i c d_{C g}: i c d_{S m}$ & Integration vector for replacement of the $i c d_{C g}$ gene by the $P_{t a c}-i c d_{S m}-r r n B T 1 T 2$ cassette & This work \\
\hline pK18mobsacB-P dapA-L1 $_{1} i c d_{S m}$ & Integration vector for replacement of the $P_{\text {tac }}$ promoter of $i c d_{S m}$ gene by the dapA-L1 promoter & This work \\
\hline pK18mobsacB-P $\mathrm{tac}-\mathrm{M}{ }^{i c d_{\mathrm{Sm}}}$ & Integration vector for replacement of the $P_{\text {tac }}$ promoter of $i c d_{S m}$ gene by the tac-M promoter & This work \\
\hline pK18mobsacB-P tuf $_{\text {icd }}$ icd & Integration vector for replacement of the $P_{t a c}$ promoter of icd $d_{S m}$ gene by the tuf promoter & This work \\
\hline pK18mobsacB-P ${ }_{\text {sod }} i c d_{\text {sm }}$ & Integration vector for replacement of the $P_{t a c}$ promoter of $i c d_{S m}$ gene by the sod promoter & This work \\
\hline
\end{tabular}


[34]. The recombinants were validated via sequencing by General Biosystems (Anhui), Inc. (Chuzhou, China).

\section{Enzyme activity assay}

The crude enzyme was prepared according to the method reported by Trigoso et al. [36]. After centrifugation at $4{ }^{\circ} \mathrm{C}$ for $30 \mathrm{~min}$ at $10,000 \times g$, the cell-free supernatants were immediately used to determine the enzyme activities. Protein concentrations were determined using the Bradford Protein Quantification Kit (Sangon, Shanghai, China) with bovine serum albumin as standard. The analyses of enzyme activities and protein concentrations were done in triplicate. Specific activity was given as the number of $\mathrm{U} \mathrm{mg}^{-1}$ of protein. The analyses of enzymes GAPDH and IDH were based on the protocol of $\mathrm{Xu}$ et al. [17] and Wang et al. [37], respectively.

\section{Quantification of intracellular NADH/NAD and NADPH/ NADP}

The intracellular NADH/NAD and NADPH/NADP were extracted as previously described by Faijes et al. [38], and their concentration were measured using NAD/NADH Quantification Colorimeteric Kit and NADP/NADPH Quantification Colorimeteric Kit (BioVision, Inc., Milpitas, CA) according to the manufacturer's instructions, respectively.

\section{Analytical methods}

A sample was taken from the shake flasks or fermenter every 2 or $4 \mathrm{~h}$. A half of sample was used to measure the biomass concentration using a spectrophotometer at $600 \mathrm{~nm}$ after an appropriate dilution. According to the previous description [17], the correlation factor between dry cell weight $(\mathrm{DCW})$ and $\mathrm{OD}_{600}$ was determined as $0.318\left(1 \mathrm{OD}_{600}=0.318 \mathrm{~g} \mathrm{DCW}\right)$. The other half of sample was diluted 100-fold, and then used to determine the glucose and L-lysine concentration using an SBA-40E immobilized enzyme biosensor (Shandong, China). The intracellular metabolites of different strains were analyzed by gas chromatography-mass spectrometry (GC-MS) according to the previous described [39]. By the end of fermentation, the fermentation liquors were also used to determine the concentration of by-products (including amino acids and organic acids) by high performance liquid chromatography (HPLC) according to the procedure described by $\mathrm{Xu}$ et al. [29]. All data were collected from three independent culture samples, and then were analyzed statistically by Student's $t$ test with a two-tailed distribution.

\section{Additional file}

Additional file 1. Additional tables.

\section{Abbreviations}

GAPDH: glyceraldehyde-3-phosphate dehydrogenase; IDH: isocitrate dehydrogenases; BCAAs: branch chain amino acids; DCW: dry cell weight; $q_{\text {Lys, max: }}$ maximal specific production rate; AEC: S-2-aminoethyl-L-cysteine; SD: sulfadiazine; FP: $\beta$-fluoro-pyruvate; GC-MS: gas chromatography-mass spectrometry; HPLC: high performance liquid chromatography.

\section{Authors' contributions}

$J X$, and WZ conceived and designed the experiments. JX and HR performed the experiments and analyzed the data. JX, XC, and FZ wrote the paper. All authors read and approved the final manuscript.

\section{Author details}

${ }^{1}$ The Key Laboratory of Industrial Biotechnology, Ministry of Education, School of Biotechnology, Jiangnan University, 1800\# Lihu Road, Wuxi 214122, China.

2 State Key Laboratory of Food Science and Technology, School of Biotechnology, Jiangnan University, 1800\# Lihu Road, Wuxi 214122, China.

\section{Acknowledgements}

We thank Prof. LM Liu from State Key Laboratory of Food Science and Technology at Jiangnan University for assistance in data analysis.

Competing interests

The authors declare that they have no competing interests.

\section{Availability of data and materials}

All data generated or analyzed during this study are included in this published article and the additional file. The authors are willing to provide any additional data and materials related to this research that may be requested for research purposes.

Consent for publication

All authors give consent to publish the research in Microbial Cell Factories.

Ethics approval and consent to participate

Not applicable.

\section{Funding}

This work was supported by the National Natural Science Foundation of China (Grant Number 31601459); the Natural Science Foundation of Jiangsu Province (Grant Number BK20150149); the China Postdoctoral Science Foundation (Grant Number 2016M590410); and National First-class Discipline Program of Light Industry Technology and Engineering (Grant Number LITE2018-07).

\section{Publisher's Note}

Springer Nature remains neutral with regard to jurisdictional claims in published maps and institutional affiliations.

Received: 13 November 2018 Accepted: 28 March 2019

Published online: 03 April 2019

\section{References}

1. Wilhelm F, Hirrlinger J. Multifunctional roles of $\left.\mathrm{NAD}^{+}\right)$and $\mathrm{NADH}$ in astrocytes. Neurochem Res. 2012;37:2317-25.

2. Agledal L, Niere M, Ziegler M. The phosphate makes a difference: cellular functions of NADP. Redox Rep. 2010;15:2-10.

3. Wang YP, San KY, Bennett GN. Cofactor engineering for advancing chemical biotechnology. Curr Opini Biotechnol. 2013;24:994-9.

4. Chen XL, Li SB, Liu LM. Engineering redox balance through cofactor systerms. Trends Biotechnol. 2014;32:337-43. 
5. Ying $\mathrm{WH} . \mathrm{NAD}\left({ }^{+}\right) / \mathrm{NADH}$ and $\mathrm{NADP}\left({ }^{+}\right) / \mathrm{NADPH}$ in cellular functions and cell death: regulation and biological consequences. Antioxid Redox Sign. 2008;10:179-206.

6. Xu JZ, Yang HK, Zhang WG. NADPH metabolism: a survey of its theoretical characteristics and manipulation strategies in amino acid biosynthesis. Crit Rev Biotechnol. 2018;38:1061-76.

7. Xu M, Qin J, Rao Z, You H, Zhang X, Yang T, Wang X, Xu Z. Effect of Polyhydroxybutyrate (PHB) storage on L-arginine production in recombinant Corynebacterium crenatum using coenzyme regulation. Microb Cell Fact. 2016;15:15.

8. Man ZW, Rao ZM, Xu MJ, Guo J, Yang TW, Zhang X, Xu ZH. Improvement of the intracellular environment for enhancing $L$-arginine production of Corynebacterium glutamicum by inactivation of $\mathrm{H}_{2} \mathrm{O}_{2}$-forming flavin reductases and optimization of ATP supply. Metab Eng. 2016;38:310-21.

9. Takeno S, Hori K, Ohtani S, Mimura A, Mitsuhashi S, Ikeda M. L-Lysine production independent of the oxidative pentose phosphate pathway by Corynebacterium glutamicum with the Streptococcus mutans gap N gene. Metab Eng. 2016;37:1-10.

10. El-Hout SI, Suzuki H, El-Sheikh SM, Hassan HMA, Harraz FA, Ibrahim IA, El-Sharkawy EA, Tsujimura S, Holzinger M, Nishina Y. Tuning the redox potential of vitamin $\mathrm{K} 3$ derivatives by oxidative functionalization using a Ag(i)/GO catalyst. Chem Commun (Camb). 2017;53:8890-3.

11. Zamboni N, Sauer U. Knockout of the high-coupling cytochrome aa(3) oxidase reduces TCA cycle fluxes in Bacillus subtilis. FEMS Microbiol Lett. 2003;226:121-6.

12. Qiao KJ, Wasylenko TM, Zhou K, Xu P, Stephanopoulos G. Lipid production in Yarrowia lipolytica is maximized by engineering cytosolic redox metabolism. Nat Biotechnol. 2017;35:173-7.

13. Xu P, Qiao K, Stephanopoulos G. Engineering oxidative stress defense pathways to build a robust lipid production platform in Yarrowia lipolytica. Biotechnol Bioeng. 2017;114:1521-30.

14. Xu JZ, Zhang JL, Guo YF, Zai YG, Zhang WG. Improvement of cell growth and L-lysine production by genetically modified Corynebacterium glutamicum during growth on molasses. J Ind Microbiol Biotechnol. 2013:40:1423-32.

15. Becker J, Wittmann C. Systems and synthetic metabolic engineering for amino acid production - the heartbeat of industrial strain development. Curr Opin Biotechnol. 2012;23:718-26.

16. Xu JZ, Han M, Zhang JL, Guo YF, Qian H, Zhang WG. Improvement of L-lysine production combines with minimization of by-products synthesis in Corynebacterium glutamicum. J Chem Technol Biotechnol. 2014:89:1924-33

17. Xu JZ, Han M, Zhang JL, Guo YF, Zhang WG. Metabolic engineering Corynebacterium glutamicum for the L-lysine production by increasing the flux into L-lysine biosynthetic pathway. Amino Acids. 2014;46:2165-75.

18. Chou HH, Marx CJ, Sauer U. Transhydrogenase promotes the robustness and evolvability of E. coli deficient in NADPH production. PLoS Genet. 2015;11:e1005007.

19. Takeno S, Murata R, Kobayashi R, Mitsuhashi S, Ikeda M. Engineering of Corynebacterium glutamicum with an NADPH-generating glycolytic pathway for L-lysine production. Appl Environ Microbiol. 2010;76:7154-60.

20. Bommareddy RR, Chen Z, Rappert S, Zeng AP. A de novo NADPH generation pathway for improving lysine production of Corynebacterium glutamicum by rational design of the coenzyme specificity of glyceraldehyde 3-phosphate dehydrogenase. Metab Eng. 2014;25:30-7.

21. Spaans SK, Weusthuis RA, van der Oost J, Kengen SWM. NADPH-generating systems in bacteria and archaea. Front Microbiol. 2015;6:742-68.

22. Komati Reddy G, Lindner SN, Wendisch VF. Metabolic engineering of an ATP-neutral Embden-Meyerhof-Parnas pathway in Corynebacterium glutamicum: growth restoration by an adaptive point mutation in NADH dehydrogenase. Appl Environ Microbiol. 2015;81:1996-2005.

23. Chen R, Yang H. A highly specific monomeric isocitrate dehydrogenase from Corynebacterium glutamicum. Arch Biochem Biophys. 2000;383:238-45.

24. Cvitkovitch DG, Gutierrez JA, Bleiweis AS. Role of the citrate pathway in glutamate biosynthesis by Streptococcus mutans. J Bacteriol. 1997;179:650-5.

25. Zhu GP, Golding GB, Dean AM. The selective cause of an ancient adaptation. Science. 2005:307:1279-82.
26. Martinez I, Zhu JF, Lin H, Bennett GN, San KY. Replacing Escherichia coli NAD-dependent glyceraldehyde 3-phosphate dehydrogenase (GAPDH) with a NADP-dependent enzyme from Clostridium acetobutylicum facilitates NADPH dependent pathways. Metab Eng. 2008;10:352-9.

27. Zhang X, Zhang RZ, Bao T, Rao ZM, Yang TW, Xu MJ, Xu ZH, Li HZ, Yang ST. The rebalanced pathway significantly enhances acetoin production by disruption of acetoin reductase gene and moderate-expression of a new water-forming NADH oxidase in Bacillus subtilis. Metab Eng. 2014;23:34-41.

28. Becker J, Klopprogge C, Schroder H, Wittmann C. Metabolic engineering of the tricarboxylic acid cycle for improved lysine production by Corynebacterium glutamicum. Appl Environ Microbiol. 2009;75:7866-9.

29. Xu JZ, Wu ZH, Gao SJ, Zhang WG. Rational modification of tricarboxylic acid cycle for improving L-lysine production in Corynebacterium glutamicum. Microb Cell Fact. 2018;17:105-18.

30. Müller T. Regulation of glutamate dehydrogenase in Corynebacterium glutamicum and its impact on nitrogen control. Köln: Universität zu Köln; 2005.

31. Jiang LY, Zhang YY, Li Z, Liu JZ. Metabolic engineering of Corynebacterium glutamicum for increasing the production of L-ornithine by increasing NADPH availability. J Ind Microbiol Biotechnol. 2013:40:1143-51.

32. Cabulong RB, Lee WK, Banares AB, Ramos KRM, Nisola GM, Valdehuesa KNG, Chung WJ. Engineering Escherichia coli for glycolic acid production from D-xylose through the Dahms pathway and glyoxylate bypass. Appl Microbiol Biotechnol. 2018;102:2179-89.

33. Xu JZ, Han M, Ren XD, Zhang WG. Modification of aspartokinase III and dihydrodipicolinate synthetase increases the production of L-lysine in Escherichia coli. Biochem Eng J. 2016;114:82-9.

34. van der Rest ME, Lange C, Molenaar D. A heat shock following electroporation induces highly efficient transformation of Corynebacterium glutamicum with xenogeneic plasmid DNA. Appl Microbiol Biotechnol. 1999;52:541-5

35. Becker J, Zelder O, Hafner S, Schroder H, Wittmann C. From zero to hero-design-based systems metabolic engineering of Corynebacterium glutamicum for L-lysine production. Metab Eng. 2011;13:159-68.

36. Trigoso YD, Evans RC, Karsten WE, Chooback L. Cloning, expression, and purification of histidine-tagged Escherichia coli dihydrodipicolinate reductase. PLoS ONE. 2016;11:e0146525.

37. Wang P, Lv C, Zhu G. Novel type II and monomeric NAD ${ }^{+}$specific isocitrate dehydrogenases: phylogenetic affinity, enzymatic characterization, and evolutionary implication. Sci Rep. 2015;5:9150.

38. Faijes M, Mars AE, Smid EJ. Comparison of quenching and extraction methodologies for metabolome analysis of Lactobacillus plantarum. Microb Cell Fact. 2007;6:27.

39. Liu LN, Duan XG, Wu J. Modulating the direction of carbon flow in Escherichia coli to improve L-tryptophan production by inactivating the global regulator FruR. J Biotechnol. 2016;231:141-8.

40. Schafer A, Tauch A, Jager W, Kalinowski J, Thierbach G, Puhler A. Small mobilizable multipurpose cloning vectors derived from the Escherichia coli plasmids pK18 and pK19-selection of defined deletions in the chromosome of Corynebacterium glutamicum. Gene. 1994;145:69-73.

Ready to submit your research? Choose BMC and benefit from:

- fast, convenient online submission

- thorough peer review by experienced researchers in your field

- rapid publication on acceptance

- support for research data, including large and complex data types

- gold Open Access which fosters wider collaboration and increased citations

- maximum visibility for your research: over $100 \mathrm{M}$ website views per year

At BMC, research is always in progress.

Learn more biomedcentral.com/submissions 